\title{
Depression and Related Factors in Patients with Parkinson's Disease at High Altitude
}

\author{
Yu Cao',* \\ Gongfeng $\mathrm{Li} \mathbb{D}^{1, *}$ \\ Jinsheng Xue ${ }^{2, *}$ \\ Guijuan Zhang' \\ Sensen Gao' \\ Yuling Huang' \\ Aiqin Zhu $\mathbb{D}^{\prime}$
}

'Institute of Geriatric, Qinghai Provincial People's Hospital, Xining, People's Republic of China; ${ }^{2}$ Foreign Cooperation Office, Chengdu Fifth People's Hospital, Chengdu, People's Republic of China

*These authors contributed equally to this work
Correspondence: Aiqin Zhu

Institute of Geriatric, Qinghai Provincial People's Hospital, No. 2 Gonghe Road, Xining, Qinghai, 8I0007, People's

Republic of China

Tel +8613139069938

Fax +869718176273

Email zhuaq@hotmail.com
Purpose: Depression seems to aggravate progression of Parkinson's disease (PD). Hypoxia stress may be one of the pathogenic factors leading to $\mathrm{PD}$. We investigated the characteristics of PD and factors related to Parkinson's disease depression (PDD) at high altitude (mean altitude $\geq 2300 \mathrm{~m}$ ).

Patients and Methods: Totally 221 PD patients of three different nationalities (Han, Hui, and Tibetan) were recruited in a high-altitude hospital. Depression was present in $55.6 \%$ of them. Patient data were examined, including demographic information, medical history, disease duration and family history. Psychopathological characteristics and motor signs were assessed by the Hamilton Depression scale (HAMD) and scales for motor and nonmotor symptoms in the Unified Parkinson's Disease Rating Scale (UPDRS). Progression of PD was evaluated by the modified Hoehn and Yahr (H-Y) staging system.

Results: Mean age ( $47.1 \%$ men) was $68.25 \pm 13.67$ years old, with disease duration of 4.18 \pm 5.13 years and median $\mathrm{H}-\mathrm{Y}$ scores $2.07 \pm 0.97$ points. Among three different nationalities, PD rate was $69.2 \%$ in Han nationals, $17.6 \%$ in Hui nationals and $13.1 \%$ in Tibetans of 221 PD patients. Compared with the non-depressed PD group, female, no-smoking and living alone rates, and dysphagia, pain, H-Y stage, ADL, UPDRS-I, UPDRS-III, HAMA, and PSQI scores were significantly increased in the PDD group, while MMSE scores were significantly decreased $(\mathrm{P}<0.05$ or $\mathrm{P}<0.01)$. PD patients of Han and Hui nationalities had increased depression rates compared with Tibetan individuals $(\mathrm{P}<0.05)$. Compared with the mild depression group, the moderate and severe depression groups had significantly increased salivation, dysphagia, H-Y stage, UPDRS-I, UPDRS-III, HAMA, and PSQI scores ( $\mathrm{P}<0.05$ or $\mathrm{P}<0.01)$. Living alone rates and ADL scores were increased in the severe depression group $(\mathrm{P}<0.05)$. Logistic regression analysis showed that living alone $(\mathrm{OR}=19.833,95 \% \mathrm{CI}$ : 2.758-142.624, $\mathrm{P}<0.01$ ), UPDRS-III score ( $\mathrm{OR}=1.079$, 95\% CI: $1.009-1.153, \mathrm{P}<0.05)$, and PSQI score ( $\mathrm{OR}=1.538,95 \% \mathrm{CI}: 1.347-1.755, \mathrm{P}<0.001)$ were risk factors for PDD. Male gender $(\mathrm{OR}=0.292$, 95\% CI: $0.112-0.763, \mathrm{P}<0.05)$ was a protective factor in PDD.

Conclusion: PDD is associated with gender, ethnicity, loneliness, non-motor symptoms (NMSs), motor symptoms, and disease severity, and depression severity. Living alone, dyskinesia, and sleep disorder are risk factors for PDD at high altitude. A relative protection against depression was observed in the Tibetan population.

Keywords: high altitude, Parkinson's disease, depression, motor symptoms, non-motor symptoms

\section{Introduction}

Parkinson's disease (PD) is a common neurological dyskinetic disease in the elderly. In addition to tremor, muscle rigidity, bradykinesia, gait, and posture abnormalities, about $30-40 \%$ of all PD patients present with non-motor symptoms 
(NMSs), including sensory symptoms, sleep disorder, autonomic dysfunction, and behavioral disorder. ${ }^{1}$ Depression is one of the most common NMSs. According to previous reports, the incidence of Parkinson's disease depression (PDD) is $2.7-90 \%,{ }^{2,3}$ for a prevalence of $11.17-22.9 \% .{ }^{4}$ PDD may accompany the course of PD, promoting the progress of PD dyskinesia, which severely affects the patients' mental health and constitutes a major contributor to poor quality of life and disability. 5,6

Previous findings demonstrated that hypoxia stress and hypoxia/intermittent hypoxia may be pathogenic factors leading to PD, although the actual mechanisms are quite unclear. ${ }^{7}$ Reportedly, patients with obstructive sleep apnea (OSA) have increased prevalence of PD, which might be related to elevated risk of hypoxia. ${ }^{8,9}$ The Qinghai-Tibetan plateau is the highest altitude in the world (average altitude $4000 \mathrm{~m}$ ), with harsh weather, sustenance, ultraviolet radiation, and hypoxia. Due to the hypoxic environment, unique culture and natural climate, lifestyle and eating habits in this region differ from those in a plain area. Qinghai Province is located in the northeast of the Qinghai-Tibetan plateau, and comprises several ethnicities, including Han, Tibetan, Hui, and other nationalities, which account for $53.04 \%, 24.44 \%, 14.83 \%$, and $7.69 \%$ of the total Qinghai population, respectively. PD is also one of the common neurodegenerative diseases in the elderly of this area, but only a few studies have assessed the characteristics of PD in different nationalities and their correlations with depression in plateau areas. Thus, the present study aimed to examine the characteristics of PD patients, PDD, and related factors of different degrees of depression to provide a basis for the treatment and prevention of $\mathrm{PD}$ in individuals living at high altitude.

\section{Patients and Methods}

\section{General Information}

From September 2017 to July 2019, data of 221 patients with idiopathic PD from the three different ethnic populations (Han, Hui, and Tibetan) were collected. The studies were performed at a movement disorder clinic with a Geriatric Department in Qinghai Provincial People's Hospital in Xining city $(2300 \mathrm{~m})$. Inclusion criteria were: (1) fulfilment of the diagnostic criteria of primary PD by the PD Society Brain Bank of the United Kingdom in $1992 ;^{10}$ (2) 30-90 years of age; (3) Hoehn and Yahr $(\mathrm{H}-\mathrm{Y})$ stages $1-5$; (4) permanent residence in Xining region; (5) voluntarily participation in this study and signed informed consent. Exclusion criteria were: (1) secondary Parkinson's syndrome caused by cerebrovascular disease, encephalitis, poisoning, trauma, and drugs, or Parkinsonism-plus syndrome; (2) mental disorder or administered oral antipsychotics; (3) severe hearing or visual loss, inability to speak or write, or other conditions that might interfere with the reliable completion of clinical assessments; (4) unwillingness to participate in this study. This study was conducted in accordance with the Declaration of Helsinki and approved by the medical Ethics Committee of Qinghai Provincial People's Hospital. Participants provided written informed consent before inclusion in this study.

\section{Methods}

For demographic data collection, a self-designed questionnaire was used to record the general information of all patients in person, including age, gender, ethnicity, education level, family life, eating habits, drinking history, tea drinking history, smoking history, family history of PD, age at onset, course of PD, constipation, salivation, hyperhidrosis, dysphagia, and pain. The patients were assessed by a neurologist (R.C.)

PD is clinically divided into three types, including the (1) tremor, (2) rigidity and (3) mixed (a patient had both tremor and rigidity as onset) types. ${ }^{11}$ Disease stage and symptoms were evaluated using the Unified Parkinson's Disease Rating Scale (UPDRS). The UPDRS includes four parts: mental, behavioral and emotional, daily life activities, and exercise examination and exercise complications. ${ }^{12}$ In addition, progression of PD patients was assessed as stages 1-5 according to the modified $\mathrm{H}-\mathrm{Y}$ staging scale. ${ }^{13}$

\section{Assessment of Depression, Anxiety, Cognition, Sleep, and Daily Living Ability}

All data were collected by face-to-face interviews in outpatient clinics. A 24-item version of the Hamilton depression rating scale (HAMD) was used to assess the severity of depression. Patients with total HAMD scores $<8$ points were included in the non-depressed group. Those with $\geq 8$ points were included in the depression group, with 8-16, $17-23$, and $\geq 24$ points representing mild, moderate, and severe depression, respectively. ${ }^{14}$ The 14 -item Hamilton Anxiety Rating Scale (HAMA) was used to assess anxiety in patients. ${ }^{15}$ The mini-mental state examination (MMSE) 
scale was used to assess the cognitive function, ${ }^{16}$ while the Pittsburgh sleep quality index (PSQI) was applied to evaluate sleep quality. ${ }^{17}$ The activities of daily living scale (ADL) was used to assess daily living ability. ${ }^{18}$

\section{Statistical Methods}

SPSS 20.0 (version 20.0, SPSS Inc., Chicago, IL, USA) was used for data analysis. All data were assessed for normality. The $t$-test was used for measurement data with normal distribution. The Chi-square test was applied for comparing enumeration data. Multiple group analysis was performed by one-way analysis of variance (ANOVA) for normally distributed data, with post-hoc least significant difference (LSD) test. Non-normally distributed data even after logarithmic transformation were expressed as median and 25th and 75th percentiles. The Kruskal-Wallis $H$-test was used for comparing multiple groups, with post-hoc Bonferroni test performed for pairwise comparisons. For study factors with a statistically significant difference after univariate analysis, binomial and ordinal multinomial logistic regression analyses were performed to identify possible risk factors for depression, whose odd ratios (ORs) and 95\% confidence intervals (CIs) were determined. $\mathrm{P}<0.05$ indicated a statistically significant difference.

\section{Results}

In this study, 221 PD patients, with an average age of $65.77 \pm 12.97$ (range, 41-89) years were included. The cohort comprised 104 men (47.1\%) and 117 women $(52.9 \%)$. The mean age $(68.25 \pm 13.67$ years $)$ of men was significantly higher than that of women $(63.71 \pm 11.86$ years) $(\mathrm{P}<0.05)$. The education level was mainly high school (7.72 \pm 5.35 years).Among the ethnic groups, PD rate was $69.2 \%$ in Han nationals, $17.6 \%$ in Hui nationals and $13.1 \%$ in Tibetans. The family/marital status was dominated by living with spouse (71.0\%). Totally $15.8 \%$ of the examined patients had a family history of PD (Table $1)$. The indicators of disease status were as follows: average duration of PD, $4.18 \pm 5.13$ years; UPDRS scores, 33.87 \pm 8.17 ; H-Y scores, $2.07 \pm 0.97$ points. The clinical types of PD were distributed as follows: 148 cases $(67.0 \%)$ with tremor type, $58(26.2 \%)$ with mixed type, and 15 (6.8\%) with rigidity type (Table 2 ).

Of the 221 PD patients, 125 (56.3\%) and 96 (43.7\%) constituted the PDD and non-depressed groups, respectively. Compared with the non-depressed PD group, female, no-smoking and living alone rates, and dysphagia, pain, H-Y stage, ADL, UPDRS-I, UPDRS-III, HAMA, and PSQI scores were significantly increased in the PDD group, while MMSE scores were significantly decreased $(\mathrm{P}<0.05$ and $\mathrm{P}<0.01$, respectively). However, no significant differences were detected in age, education level, dietary habits, tea drinking history, alcohol drinking history, family history of PD, constipation, salivation, sweating, UPDRS-II, PD clinical type, and course of PD between the two groups $(\mathrm{P}>0.05)$ (Tables 1 and 2).

Factors with statistically significant differences in univariate analysis were taken as independent variables, while depression was considered a dependent variable for binary logistic regression analysis. After adjustment for age, ethnicity, UPDRS-I score and anxiety severity assessed by the HAMA scale, living alone $(\mathrm{OR}=19.833,95 \%$ CI: 2.758-142.624, $\mathrm{P}<0.01$ ), elevated UPDRS-III ( $\mathrm{OR}=1.079$, 95\% CI: $1.009-1.153, \mathrm{P}<0.05)$, and elevated PSQI score $(\mathrm{OR}=1.538,95 \%$ CI: $1.347-1.755, \mathrm{P}<0.001)$ were risk factors for the occurrence of depression in PD patients. The risk of depression was lower in men compared with women $(\mathrm{OR}=0.292,95 \%$ CI: 0.112-0.763, $\mathrm{P}<0.05$ ) (Table 3).

The 125 patients in the PDD group included 77 with mild depression (61.6\%), 33 with moderate depression (26.4\%), and 15 with severe depression (12.0\%). We found that PD patients of Han and Hui nationalities in the mild, moderate, and severe depression groups were more numerous than Tibetan counterparts $(\mathrm{P}<0.05)$. Compared with the mild depression group, salivation and dysphagia rates in PD patients were significantly increased $(\mathrm{P}<0.05)$ in the moderate and severe depression groups. In addition, living alone rate in PD patients of the severe depression group was higher than those of the mild and moderate depression groups $(\mathrm{P}<0.05)$. However, no significant differences were found among the three groups in age, gender, education level, dietary habits, drinking history, tea drinking history, smoking history, constipation, family history, and clinical types of PD ( $>>0.05)$. The Kruskal-Wallis test showed that H-Y stage, and UPDRSI, UPDRS-III, HAMA, and PSQI scores were significantly higher in the moderate and severe depression groups compared with the mild depression group $(\mathrm{P}<0.05$ and $\mathrm{P}<0.01$, respectively). ADL scores were significantly higher in the severe depression group compared with the mild and moderate depression groups $(\mathrm{P}<0.05)$. However, no significant differences were observed in disease course, and UPDRSII and MMSE scores among the three groups $(\mathrm{P}>0.05)$ (Table 4). 
Table I Demographics in the Depression and Non-Depressed Groups of Patients with PD at High Altitude [N (\%)].

\begin{tabular}{|c|c|c|c|c|c|c|}
\hline Items & & $\begin{array}{c}\text { Total } \\
(\mathrm{N}=22 \mathrm{I})\end{array}$ & $\begin{array}{l}\text { Depression Group } \\
\qquad(\mathrm{N}=\mid 25)\end{array}$ & $\begin{array}{l}\text { Non-Depressed Group } \\
\qquad(\mathrm{N}=96)\end{array}$ & $\chi^{2}$ & P-value \\
\hline Gender & $\begin{array}{l}\text { Male } \\
\text { Female }\end{array}$ & $\begin{array}{l}104(47.1) \\
117(52.9)\end{array}$ & $\begin{array}{l}47(37.6) \\
78(62.4)\end{array}$ & $\begin{array}{l}57(59.4) \\
39(40.6)\end{array}$ & 10.334 & 0.001 \\
\hline Nationality & $\begin{array}{l}\text { Han } \\
\text { Hui } \\
\text { Tibetan }\end{array}$ & $\begin{array}{l}153(69.2) \\
39(17.6) \\
29(13.1)\end{array}$ & $\begin{array}{c}85(68.0) \\
28(22.4) \\
12(9.6)\end{array}$ & $\begin{array}{l}68(70.8) \\
11(11.5) \\
17(17.7)\end{array}$ & 6.467 & 0.039 \\
\hline Education & $\begin{array}{l}\text { Illiteracy } \\
\text { Primary } \\
\text { Junior middle } \\
\text { Above high school }\end{array}$ & $\begin{array}{l}58(26.2) \\
51(23.1) \\
42(19.0) \\
70(31.7)\end{array}$ & $\begin{array}{ll}39 & (31.2) \\
31 & (24.8) \\
22 & (17.6) \\
33 & (26.4)\end{array}$ & $\begin{array}{l}19(19.8) \\
20(20.8) \\
20(20.8) \\
37(38.5)\end{array}$ & 5.889 & 0.117 \\
\hline Marital status & $\begin{array}{l}\text { Living alone } \\
\text { Living with spouse } \\
\text { Living with children }\end{array}$ & $\begin{array}{l}23(10.4) \\
157(7 \mid .0) \\
41(18.6)\end{array}$ & $\begin{array}{l}20(16.0) \\
81(64.8) \\
24(19.2)\end{array}$ & $\begin{array}{c}3(3.1) \\
76(79.2) \\
17(17.7)\end{array}$ & 10.291 & 0.006 \\
\hline Eating habits & $\begin{array}{l}\text { Meat } \\
\text { Vegetarian } \\
\text { Meat and } \\
\text { vegetarian }\end{array}$ & $\begin{array}{c}29(13.1) \\
69(31.2) \\
123(55.7)\end{array}$ & $\begin{array}{l}16(12.8) \\
45(36.0) \\
64(51.2)\end{array}$ & $\begin{array}{l}13(13.5) \\
24(25.0) \\
59(61.5)\end{array}$ & 3.154 & 0.207 \\
\hline Tea & & II 8 (53.4) & $66(52.8)$ & $52(54.2)$ & 0.041 & 0.840 \\
\hline Drinking & & $58(26.2)$ & $28(22.4)$ & $30(3 \mid .2)$ & 2.197 & 0.138 \\
\hline Smoking & & $5 I(23.1)$ & $21(16.8)$ & $30(3 \mid .2)$ & 6.387 & 0.011 \\
\hline Family history & & $35(15.8)$ & $21(16.8)$ & $14(14.6)$ & 0.200 & 0.655 \\
\hline Constipation & & $107(48.4)$ & $65(52.0)$ & $42(43.8)$ & 1.480 & 0.224 \\
\hline Hyperhidrosis & & I 30 (58.8) & $78(62.4)$ & $52(54.2)$ & 1.520 & 0.218 \\
\hline Salivary & & $90(40.7)$ & $54(43.2)$ & $36(37.5)$ & 0.731 & 0.393 \\
\hline Dysphagia & & $16(7.2)$ & 14 (I I.2) & $2(2.1)$ & 6.720 & 0.010 \\
\hline Pain & & $78(35.3)$ & $56(44.8)$ & $22(22.9)$ & 11.386 & 0.001 \\
\hline Clinical typing & $\begin{array}{l}\text { Tremor } \\
\text { Ankylosis } \\
\text { Mixed }\end{array}$ & $\begin{array}{l}148(67.0) \\
15(6.8) \\
58(26.2)\end{array}$ & $\begin{array}{c}83(66.4) \\
8(7.2) \\
33(26.4)\end{array}$ & $\begin{aligned} 65 & (67.7) \\
6 & (6.2) \\
25 & (26.0)\end{aligned}$ & 0.089 & 0.957 \\
\hline
\end{tabular}

Notes: Chi-squared test. $\mathrm{P}<0.05$ indicated statistical significance.

\section{Discussion}

Currently, the incidence of PD is gradually increasing, and the hypoxic environment may have some influence on the disease. A recent study indicated that the hypoxia factor might be associated with the onset of PD. ${ }^{19}$ It was reported that low-pressure and hypoxic environment alters the permeability of the blood-brain barrier, leading to the secretion of lipopolysaccharide (LPS), which plays a major role in the occurrence and progression of $\mathrm{PD} .{ }^{20}$ However, few reports on the clinical study of PD in the hypoxia environment are available. This study is the first to examine the characteristics of PD in high plateau populations. As shown above, the mean age of men with PD was significantly higher than that of women. The marital status was dominated by living with spouse (71.0\%), and $15.8 \%$ of all patients had a family history of PD. Currently, only a few studies are available on the correlation between PD and ethnicity, with none performed in China. Chinese studies have shown that in Guizhou Province, PD prevalence in ethnic minorities is higher than that of Han individuals, with a prevalence of $1.1 \%(36 / 3274)$ in Uighur individuals being higher than $0.7 \%(21 / 2871)$ found in Han 
Table 2 Comparison of Clinical Status Between the Depression and Non-Depressed Groups of 22I Patients with PD at High Altitude $(\overline{\mathrm{X}} \pm \mathrm{SD})$

\begin{tabular}{|l|c|c|c|c|c|}
\hline Items & Total (N=22I) & Depression Group (N=I 25) & Non-Depressed Group (N=96) & t-test & P-value \\
\hline Age (years) & $65.77 \pm 12.97$ & $65.8 I \pm 11.89$ & $65.73 \pm 14.31$ & 0.045 & 0.964 \\
Course of disease (years) & $4.18 \pm 5.13$ & $4.21 \pm 4.69$ & $4.14 \pm 5.68$ & 0.097 & 0.923 \\
UPDRS part I & $4.70 \pm 4.53$ & $7.26 \pm 4.43$ & $1.35 \pm 1.34$ & 12.619 & $<0.001$ \\
UPDRS part II & $11.49 \pm 7.34$ & $11.66 \pm 7.69$ & $11.27 \pm 6.88$ & 0.386 & 0.700 \\
UPDRS part III & $17.68 \pm 12.68$ & $22.31 \pm 13.96$ & $13.36 \pm 9.61$ & 5.635 & $<0.001$ \\
H-Y stage & $2.07 \pm 0.97$ & $2.20 \pm 0.99$ & $1.89 \pm 0.92$ & 2.364 & 0.019 \\
ADL & $26.46 \pm I 1.23$ & $27.97 \pm 12.75$ & $24.97 \pm 9.46$ & 2.008 & 0.046 \\
MMSE & $24.92 \pm 4.31$ & $24.06 \pm 4.61$ & $26.04 \pm 3.60$ & -3.582 & $<0.001$ \\
HAMA & $8.06 \pm 5.73$ & $11.33 \pm 5.21$ & $3.80 \pm 2.88$ & 13.660 & $<0.001$ \\
PSQI & $6.24 \pm 4.91$ & $8.74 \pm 3.89$ & $3.39 \pm 3.06$ & 11.438 & $<0.001$ \\
HAMD & $10.68 \pm 8.40$ & $15.94 \pm 7.51$ & $3.76 \pm 2.28$ & 17.147 & $<0.001$ \\
\hline
\end{tabular}

Notes: T-test of data expressed as mean \pm SD. $P<0.05$ indicated statistical significance.

Abbreviations: UPDRS-I, Unified Parkinson's Disease Rating Scale-I; UPDRS-II, Unified Parkinson's Disease Rating Scale-II; UPDRS-III, Unified Parkinson's Disease Rating Scale-III; H-Y stage, Hoehn-Yahr stage; ADL, activities of daily living scale; MMSE, mini-mental state examination; HAMA, Hamilton anxiety; HAMD, Hamilton depression; PSQI, Pittsburgh sleep quality index.

individuals in Xinjiang. ${ }^{21}$ The population of the QinghaiTibet plateau consists mainly of native Tibetan, Han, and Hui nationals that migrated to the plateau. Due to their unique historical and cultural background as well as the natural living environment, high-altitude populations have probably developed different strategies to adapt to the multiple stressors in their environment. To the best of our knowledge, this is the first study reporting the rates of PD in Han, Hui and Tibetan nationalities in high-altitude areas, which were about $69.2 \%, 17.6 \%$ and $13.1 \%$, respectively. These results showed Tibetan patients were less likely than Han and Hui patients to develop PD.PD is clinically divided into tremor, rigidity, and mixed types.
A study showed that most PD patients clinically belong to the tremor type, followed by the rigidity and mixed types. $^{22}$ This study demonstrated that the tremor type was the most common, with 148 cases $(67.0 \%)$, followed by the mixed (58 cases, 26.2\%), and rigidity (15 cases, $6.8 \%$ ) types. The results were similar to previous findings by our group, where $631 \mathrm{PD}$ patients were enrolled from 2011 to 2016, and the tremor type was dominant (45.0\%), followed by the mixed $(29.5 \%)$ and rigidity $(25.5 \%)$ types. $^{23}$ This result of tremor type predominance corroborated previous findings. ${ }^{24}$ However, the rigidity type was less represented than previously reported globally. The underlying reasons are unclear and require an in-depth

Table 3 Multivariate Regression Analysis of Depression in 22I Patients with PD at High Altitude

\begin{tabular}{|l|c|c|c|c|c|c|}
\hline & B & S.E & Wals & P-value & OR & 95\% CI \\
\hline Male & -1.231 & 0.490 & 6.318 & 0.012 & 0.292 & $0.112-0.763$ \\
Living alone & 2.987 & 1.007 & 8.808 & 0.003 & 19.833 & $2.758-142.624$ \\
Living with spouse & 0.738 & 0.586 & 1.584 & 0.208 & 2.092 & $0.663-6.602$ \\
Smoking & 0.320 & 0.564 & 0.322 & 0.570 & 1.378 & $0.456-4.161$ \\
Dysphagia & -0.588 & 1.300 & 0.205 & 0.651 & 0.555 & $0.043-7.100$ \\
Pain & 0.182 & 0.466 & 0.152 & 0.697 & 1.199 & $0.48 I-2.990$ \\
UPDRS-III & 0.076 & 0.034 & 4.909 & 0.027 & 1.079 & $1.009-1.153$ \\
H-Y stage & -0.486 & 0.328 & 2.198 & 0.138 & 0.615 & $0.324-1.169$ \\
ADL & -0.033 & 0.032 & 1.065 & 0.302 & 0.968 & $0.909-1.030$ \\
MMSE & -0.090 & 0.051 & 3.082 & 0.079 & 0.914 & $0.827-1.010$ \\
PSQI & 0.430 & 0.068 & 40.591 & 0.000 & 1.538 & $1.347-1.755$ \\
Constant & 0.607 & 2.161 & 0.079 & 0.779 & 1.836 & \\
\hline
\end{tabular}

Notes: A binary logistic regression analysis (method=ENTER) model was used. The relative risk ratio was calculated. $P<0.05$ indicated statistical significance. Abbreviations: OR, odds ratio; Cl, confidence interval; UPDRS, Unified Parkinson's Disease Rating Scale; $\mathrm{H}$-Y stage, Hoehn-Yahr stage; ADL, Activities of daily living scale; MMSE, mini-mental state examination; HAMA, Hamilton anxiety; HAMD, Hamilton depression; PSQI, Pittsburgh sleep quality index. 
Table 4 Comparative Analysis of Related Indexes Among the Three Groups of 125 Patients with PD with Different Degrees of

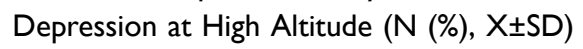

\begin{tabular}{|c|c|c|c|c|c|c|}
\hline Items & & $\begin{array}{l}\text { Mild Depression } \\
\qquad(\mathbf{N}=77)\end{array}$ & $\begin{array}{l}\text { Moderate Depression } \\
\qquad(\mathrm{N}=33)\end{array}$ & $\begin{array}{l}\text { Severe Depression } \\
\qquad(\mathrm{N}=15)\end{array}$ & $\begin{array}{c}\chi^{2} / \mathbf{F} / \\
\mathbf{H}\end{array}$ & P-value \\
\hline Age (years) & & $64.37 \pm|2.5|$ & $68.88 \pm 9.68$ & $65.33 \pm 11.45$ & 1.715 & 0.184 \\
\hline Gender & $\begin{array}{l}\text { Male } \\
\text { Female }\end{array}$ & $\begin{array}{l}29(37.7) \\
48(62.3)\end{array}$ & $\begin{array}{l}14(42.4) \\
19(57.6)\end{array}$ & $\begin{array}{l}4(26.7) \\
\text { II (73.3) }\end{array}$ & 1.092 & 0.579 \\
\hline Nationality & $\begin{array}{l}\text { Han } \\
\text { Hui } \\
\text { Tibetan }\end{array}$ & $\begin{array}{l}51(66.2) \\
15(19.5) \\
11(14.3)\end{array}$ & $\begin{array}{c}20(60.6) \\
12(36.4) \\
1(3.0)\end{array}$ & $\begin{array}{c}\text { I4 (93.3) } \\
\text { I (6.7) } \\
0(0.0)\end{array}$ & 9.731 & 0.033 \\
\hline Education & $\begin{array}{l}\text { Illiteracy } \\
\text { Primary } \\
\text { Junior middle } \\
\text { Above high } \\
\text { school }\end{array}$ & $\begin{array}{l}24(31.2) \\
17(22.1) \\
17(22.1) \\
19(24.7)\end{array}$ & $\begin{array}{l}11(33.3) \\
12(36.4) \\
2(6.1) \\
8(24.2)\end{array}$ & $\begin{array}{l}4(26.7) \\
2(13.3) \\
3(20.0) \\
6(40.0)\end{array}$ & 7.607 & 0.259 \\
\hline Marital status & $\begin{array}{l}\text { Living alone } \\
\text { Living with } \\
\text { spouse } \\
\text { Living with } \\
\text { children }\end{array}$ & $\begin{array}{l}10(13.0) \\
57(74.0) \\
10(13.0)\end{array}$ & $\begin{array}{c}3(9.1) \\
20(60.6) \\
10(30.3)\end{array}$ & $\begin{array}{c}7(46.7)^{* \#} \\
4(26.7) \\
4(26.7)\end{array}$ & 16.810 & 0.001 \\
\hline Eating habits & $\begin{array}{l}\text { Meat } \\
\text { Vegetarian } \\
\text { Meat and } \\
\text { vegetarian }\end{array}$ & $\begin{array}{l}\text { II (14.3) } \\
26(33.8) \\
40(51.9)\end{array}$ & $\begin{array}{c}4(12.1) \\
13(39.4) \\
16(48.5)\end{array}$ & $\begin{array}{c}\text { I (6.7) } \\
6(40.0) \\
8(53.3)\end{array}$ & 0.824 & 0.951 \\
\hline Tea & & $39(50.6)$ & $21(63.6)$ & $6(40.0)$ & 2.684 & 0.261 \\
\hline Drinking & & $20(26.0)$ & $7(2 \mid .2)$ & I (6.7) & 2.544 & 0.276 \\
\hline $\begin{array}{l}\text { Smoking } \\
\text { Family history }\end{array}$ & & $\begin{array}{l}14(18.2) \\
12(15.6)\end{array}$ & $\begin{array}{l}5(15.2) \\
7(2 \mid .2)\end{array}$ & $\begin{array}{l}2(13.3) \\
2(13.3)\end{array}$ & $\begin{array}{l}0.217 \\
0.695\end{array}$ & $\begin{array}{l}0.940 \\
0.775\end{array}$ \\
\hline Constipation & & $36(46.8)$ & $21(63.6)$ & $8(53.3)$ & 2.650 & 0.266 \\
\hline $\begin{array}{l}\text { Hyperhidrosis } \\
\text { Salivary }\end{array}$ & & $\begin{array}{l}49(63.6) \\
25(32.5)\end{array}$ & $\begin{array}{l}18(54.5) \\
20(60.6)^{*}\end{array}$ & $\begin{array}{l}\text { II (73.3) } \\
9(60.0)\end{array}$ & $\begin{array}{l}1.682 \\
9.415\end{array}$ & $\begin{array}{l}0.431 \\
0.009\end{array}$ \\
\hline Dysphagia & & $3(3.9)$ & $7(21.2)^{*}$ & $4(26.7)^{*}$ & 11.146 & 0.002 \\
\hline Pain & & $29(37.7)$ & 17 (5I.5) & $10(66.7)$ & 5.088 & 0.079 \\
\hline Clinical typing & $\begin{array}{l}\text { Tremor } \\
\text { Ankylosis } \\
\text { Mixed }\end{array}$ & $\begin{array}{c}50(64.9) \\
7(9.1) \\
20(26.0)\end{array}$ & $\begin{array}{c}26(78.8) \\
2(6.1) \\
5(15.2)\end{array}$ & $\begin{array}{c}7(46.7) \\
0(0) \\
8(53.3)\end{array}$ & 7.584 & 0.087 \\
\hline $\begin{array}{l}\text { Course of } \\
\text { disease }\end{array}$ & & $2(1,4.25)$ & $4(1.75,7)$ & $3(1,5)$ & 3.391 & 0.184 \\
\hline UPDRS part I & & $5(2.5,8)$ & $10(7.5,13.5)^{* *}$ & II $(9,13)^{* *}$ & 29.682 & $<0.001$ \\
\hline UPDRS part II & & $9(5.5,13.5)$ & II $(6,19)$ & $13(9,17)$ & 1.682 & 0.190 \\
\hline UPDRS part III & & $15(10.5,23)$ & $27(18.5,38)^{* *}$ & $32(18,42)^{* *}$ & 25.041 & $<0.001$ \\
\hline ADL & & $20(20,26)$ & $23(20,37.5)$ & $28(20,49)^{*}$ & 6.489 & 0.039 \\
\hline MMSE & & $26(22,28)$ & $24(20,27)$ & $25(19,28)$ & 1.166 & 0.558 \\
\hline
\end{tabular}

(Continued) 
Table 4 (Continued).

\begin{tabular}{|c|c|c|c|c|c|}
\hline Items & $\begin{array}{l}\text { Mild Depression } \\
\qquad(\mathrm{N}=\mathbf{7 7})\end{array}$ & $\begin{array}{l}\text { Moderate Depression } \\
\qquad(\mathrm{N}=33)\end{array}$ & $\begin{array}{l}\text { Severe Depression } \\
(\mathrm{N}=15)\end{array}$ & $\begin{array}{c}\chi^{2} / \mathbf{F} / \\
\mathbf{H}\end{array}$ & P-value \\
\hline HAMA & $9(7,12)$ & II $(9,15.5)^{*}$ & $16(13,22)^{* *}$ & $25.88 I$ & $<0.001$ \\
\hline PSQI & $7(4,9)$ & II $(10,13)^{* *}$ & $13(9,15)^{* *}$ & 43.020 & $<0.001$ \\
\hline
\end{tabular}

Notes: Chi-squared test: $\mathrm{P}<0.05$ indicated statistical significance. $* \mathrm{P}<0.05$, compared to the mild depression group; \#P<0.05, compared to the moderate depression group. Kruskal-Wallis test (data expressed as median and quartile ranges): $* \mathrm{P}<0.05$ and $* * \mathrm{P}<0.01$, compared to the mild depression group; \#P<0.05, compared to the moderate depression group.

Abbreviations: PD, Parkinson's disease; PDD, Parkinson's disease depression; ADL, Activity of Daily living scale; HAMD, Hamilton Depression scale; HAMA, Hamilton anxiety scales; UPDRS-I, Unified Parkinson's Disease Rating Scale-I; UPDRS-II, Unified Parkinson's Disease Rating Scale-II; UPDRS-III, Unified Parkinson's Disease Rating Scale-III; PSQI, Pittsburgh Sleep quality Index; NMSs, non-motor symptoms; OSA, Obstructive sleep apnea; MMSE, mini-mental state examination; ANOVA, Analysis of Variance; LSD, least significant difference; RR, relevant risk; OR, odds ratio; Cl, confidence interval; LPS, lipopolysaccharide.

investigation. Furthermore, we also assessed the characteristics of PD at high altitude: average duration of PD was $4.18 \pm 5.13$ years; UPDRS scores were $33.87 \pm 8.17$, and $\mathrm{H}-\mathrm{Y}$ stages were $2.07 \pm 0.97$. Moreover, there were nonmotor symptoms such as constipation of different degrees, salivation, excessive sweating, depression, anxiety, and daily life ability and cognitive decline at high altitude. A possible reason is that the hypoxic environment induces low oxygen content in elderly individuals at high altitude, resulting in declined nervous system function and accelerated brain tissue aging. ${ }^{25}$ This phenomenon might also be attributed to the less developed healthcare in the area, especially the shortage of specialists. For example, only one Grade A tertiary hospital in the province has a PD specialist clinic. Also, clinicians have not focused on the patients of this region; thus, systematic and standardized treatments and effective drugs are lacking. Consequently, these patients have not been diagnosed and treated promptly.

Depression is the most common NMS in PD patients. It seems to aggravate the progression of the disease's motor and cognitive impairments, and is also one of the main causes of declined quality of life. ${ }^{26}$ The prevalence of depression in PD varies widely in different studies $(2.7-90 \%)^{3}$ We collected data for a number of disease and lifestyle features that could be linked to the development of depression in this population. Of the $221 \mathrm{PD}$ patients, $125(55.6 \%)$ presented depression, similar to the rate reported by Pinto et al. ${ }^{27}$ However, this rate was higher than found in Xinjiang patients $(42.2 \%){ }^{28}$ A previous study established a correlation between gender and PDD, ${ }^{29}$ and showed that PDD prevalence is significantly higher in females (62.4\%) compared with males (37.6\%). Logistic regression analysis revealed that men had a lower risk of depression, which could be attributed to lower education level and more mental disorders and pain in women; also, the additional psychosocial factor renders women prone to develop depression in the plateau area. Currently, only a few studies have established a correlation between nationality and PDD. This study found that the rates of PDD in Han (68.0\%) and Hui $(22.4 \%)$ nationals were significantly higher than that of Tibetans (7.0\%). This phenomenon might be explained by the fact that Tibetans are not susceptible to PD owing to their adaptability to high plateaus. Elderly Tibetans have lower living pressure and much lower mental stress than Han and Hui nationals. ${ }^{30}$ In addition, their religious beliefs, lifestyle, eating habits, and other factors differ from those of Han and Hui migrants. Due to the relatively small sample size, differences among ethnicities cannot be excluded in the selected area. Thus, larger interventional studies may help demonstrate high plateau adaptability and ethnicity differences in the future.

Jormet al. reported that people living alone are susceptible to PDD. ${ }^{31} \mathrm{Cui}$ et al also demonstrated that lack of a sexual partner is a risk factor for PDD. ${ }^{4}$ In agreement, the above results also showed significantly higher rate of individuals living alone among PDD patients $(16.0 \%)$ compared with the non-depressed group (3.1\%).Logistic regression analysis revealed that living alone was a risk factor for depression in PD patients. These results indicated that concern and care of the family, especially the spouse, is beneficial for PDD improvement, whereas elderly individuals living alone are at risk of PDD at high altitude. In recent years, the correlation between smoking and PD has attracted increasing attention. Hernán et al reported that smoking may be a protective factor of $\mathrm{PD}$, and is negatively correlated with the occurrence of $\mathrm{PD} .^{32}$ The present study showed that the rate of smokers was lower in the 
depression group (16.8\%) compared with the nondepressed group (31.2\%). Autonomic dysfunction in PD is considered a late complication of the disease. Notably, with the progression of the disease, dyskinesia is aggravated, and PD patients exhibit autonomic dysfunction, including in continence, dysphagia, myalgia, constipation, hyperhidrosis, cardiovascular dysfunction, and body temperature regulation disorder. ${ }^{10,33,34}$ Assessment of NMSs showed that dysphagia, pain, ADL, MMSE, and HAMA scores were higher in the PDD group compared with the PD non-depressed group, and MMSE scores in the PDD group were lower than those of the nondepressed group. These findings suggested that PDD patients are accompanied by dysphagia, mainly skeletal muscle pain, anxiety, and cognitive decline. Several investigators have assessed the correlation between sleep disorder and PD. Sleep disorders affect up to $60-90 \%$ of PD patients, with increasing prevalence as the disease progresses. ${ }^{35}$ It was reported that individuals living at high altitudes have severe sleep disorder, with the degree of change showing high correlations with altitude height and the duration of stay on a plateau area. $^{36}$ This phenomenon suggested that PSQI scores were significantly higher in the PDD group compared with the non-depressed PD group. Further logistic regression analysis found that sleep disorder was a risk factor for depression in PD patients. These findings suggested that sleep disorder has a significant impact on PDD, which might increase the risk of PD dyskinesia through chronic hypoxia.

The results of the current study are consistent with those showing the effect of depression on motor function and disease severity in PD. ${ }^{37}$ Furthermore, in this study, PDD patients had higher H-Y stages and UPDRS-III scores compared with the PD non-depressed group. Further logistic regression analysis revealed that PD severity was a risk factor for PDD. These results suggested that depression is related to tremor, dyskinesia, and gait instability, and increases the severity of PD. Limited activity, the need for long-term drug treatment and stigma bring severe psychological pressure to patients, which in turn affects physical and mental health as well as quality of life in patients, imposing a great burden on patients and their families. Therefore, depression and motor symptoms/wellbeing are highly intertwined in patients with PD living at high altitude.

Herein, we investigated the different degrees of depressive symptoms that might contribute to increased disability in the 125 patients of the PDD group. Based on the HAMD cutoff scores, $61.6 \%$ patients had mild depression, $26.4 \%$ had moderate depression, and $12.0 \%$ had severe depression. In addition, there were more PD patients of Han and Hui nationalities in the mild, moderate, and severe depression groups than Tibetans. Tibetan people have forged their national character of perseverance, heroism, optimism, and open-mindedness. ${ }^{38,39}$ Under the influence of traditional national culture, PD patients of Tibet nationality maintain an optimistic view of life and death, which contributes to their healthy and stable psychological form and helps them gain confidence. The present study investigated the association between the degree of depression and living status (whether living alone or with others) in PD patients, and revealed a high rate of depression among individuals living alone in the severe depression PD group (46.7\%), which was higher than those of the mild $(13.0 \%)$ and moderate $(9.1 \%)$ depression groups. These PD patients lived without family support and had limited access to community resources. Thus, they were isolated from the society. These findings indicated that living with someone is a major factor in the prevention of PDD. Recently, it was reported that the prevalence rates of dyskinesia and gait instability show an increasing trend in PD patients with moderate and severe depression, and depression and motor symptoms/quality of life are highly intertwined in PD patients. ${ }^{40}$ Intriguingly, UPDRS-I and UPDRS-III scores as well as H-Y stages were significantly higher in PD patients with moderate and severe depression than in the mild depression group. In addition, ADL scores were higher in the severe depression group compared with the mild and moderate depression groups. These results confirmed aggravated dyskinesia, reduced daily living ability, and altered quality of life at high altitude. Furthermore, our results showed that dyskinesia, salivation, dysphagia, and sleep disorders were obvious in PD patients with moderate and severe depression. The possible causes include the vastness of the area, lack of transportation, and self-abasement, which reduce social activities, thereby aggravating depression. ${ }^{41}$ Therefore, doctors in plateau areas need to focus on severe PD patients' mood, family life, living habits, sleep quality, and autonomic dysfunction besides motor function for accurate diagnosis, intervention, and treatment at the earliest possible time.

Currently, PD research on a plateau area is lacking internationally. Although this study provided significant guidance for clinical prevention and treatment of the 
disease, it had some limitations. First, only one area was examined. Due to ethnicity, area, and other differences, the results may not be applied to other populations. In addition, the sample size was relatively small. Therefore, a large sample multicenter study is needed to comprehensively assess high-altitude populations.

\section{Conclusion}

Overall, the rates of PD are higher in Han (69.2\%) and Hui (17.6\%) immigrants compared with native Tibetans (13.1\%) at high altitude. PDD is associated with gender, living alone, salivation, dysphagia, anxiety, cognitive impairment, sleep disorders, motor symptoms, and disease severity. Tibetan PD patients are less likely than Han or Hui counterparts to present with depression. Living alone, dyskinesia, and sleep disorder are risk factors for PDD. Male PD patients have a low risk of depression than females. Moderate and severe depression can aggravate motor and non-motor symptoms in PD patients, leading to declined daily living ability and quality of life at high altitude.

\section{Acknowledgments}

The authors would like to thank Dr. David Wang and Chunfeng Liu for critically reviewing the manuscript. The authors would also like to acknowledge the patients and their families for their participation in this study. The authors are grateful to the Medical School of Qinghai University and the Qinghai Center Laboratory of Qinghai Provincial People's Hospital for helpful comments and feedback throughout this study.

The abstract of this paper was presented at the XXVI World Congress on Parkinson's Disease and Related Disorders as a poster presentation with interim findings. The poster's abstract was published in "Poster Abstracts" in the journal Parkinsonism and Related Disorders (PRD), My abstract Title: "Related with risk factors of depression in Parkinson's disease at high altitude "New Number: A 084.

\section{Funding}

This work was supported by the Qinghai Province Application of Basic Research Projects (number: 2019SF-135) and the National Natural Science Foundation of China (NO: 201608635002).

\section{Disclosure}

The authors report no conflicts of interest in this work.

\section{References}

1. Chaudhuri KR, Martinez-Martin P, Schapira AH, et al. International multicenter pilot study of the first comprehensive self-completed nonmotor symptoms questionnaire for Parkinson's disease: the NMSQuest study. Mov Disord. 2006;21(7):916-923. doi:10.1002/ mds. 20844

2. Timmer MHM, van Beek M, Bloem BR, Esselink RAJ. What a neurologist should know about depression in Parkinson's disease. Pract Neurol. 2017;17(5):359-368. doi:10.1136/practneurol-2017001650

3. Reijnders JS, Ehrt U, Weber WE, Aarsland D, Leentjens AF. A systematic review of prevalence studies of depression in Parkinson's disease. Mov Disord. 2008;23(2):183-189. doi:10.1002/ mds. 21803

4. Cui SS, Du JJ, Fu R, et al. Prevalence and risk factors for depression and anxiety in Chinese patients with Parkinson disease. BMC Geriatr. 2017;17(1):270. doi:10.1186/s12877-017-0666-2

5. Ishihara L, Brayne C. A systematic review of depression and mental illness preceding Parkinson's disease. Acta Neurol Scand. 2006;113 (4):211-220. doi:10.1111/j.1600-0404.2006.00579.x

6. Baquero M, Martín N. Depressive symptoms in neurodegenerative diseases. World J Clin Cases. 2015;3(8):682-693. doi:10.12998/wjcc. v3.i8.682

7. Onodera H, Okabe S, Kikuchi Y, Tsuda T, Itoyama Y. Impaired chemosensitivity and perception of dyspnoea in Parkinson's disease. Lancet. 2000;356(9231):739-740. doi:10.1016/S0140-6736(00) 02638-6

8. Yeh NC, Tien KJ, Yang CM, Wang JJ, Weng SF. Increased Risk of Parkinson's Disease in Patients With Obstructive Sleep Apnea: a Population-Based, Propensity Score-Matched, Longitudinal Follow-Up Study. Medicine. 2016;95(2):e2293. doi:10.1097/ MD.0000000000002293

9. Meng L, Benedetti A, Lafontaine AL, et al. Obstructive sleep apnea, CPAP therapy and Parkinson's disease motor function: a longitudinal study. Parkinsonism Relat Disord. 2020;70:45-50. doi:10.1016/j. parkreldis.2019.12.001

10. Hughes AJ, Daniel SE, Kilford L, Lees AJ. Accuracy of clinical diagnosis of idiopathic Parkinson's disease: a clinico-pathological study of 100 cases. J Neurol Neurosurg Psychiatry. 1992;55 (3):181-184. doi:10.1136/jnnp.55.3.181

11. Schiess MC, Zheng H, Soukup VM, Bonnen JG, Nauta HJ. Parkinson's disease subtypes: clinical classification and ventricular cerebrospinal fluid analysis. Parkinsonism Relat Disord. 2000;6 (2):69-76. doi:10.1016/S1353-8020(99)00051-6

12. Ramaker C, Marinus J, Stiggelbout AM, Hilten BJV. Systematic evaluation of rating scales for impairment and disability in Parkinson's disease. Mov Disord. 2002;17(5):867-876. doi:10.1002/ mds. 10248

13. Borromei A, Caramelli R, Chieregatti G, et al. Ability and fitness to drive of Parkinson's disease patients. Funct Neurol. 1999;14 (4):227-234.

14. Zimmerman M, Martinez JH, Young D, Chelminski I, Dalrymple K. Severity classification on the Hamilton Depression Rating Scale. J Affect Disord. 2013;150(2):384-388. doi:10.1016/j.jad.2013.04.028

15. Hamilton M. The assessment of anxiety states by rating. $\mathrm{Br} \mathrm{J} \mathrm{Med}$ Psychol. 1959;32(1):50-55. doi:10.1111/j.2044-8341.1959.tb00467.x

16. Folstein MF, Folstein SE, McHugh PR. "Mini-mental state". A practical method for grading the cognitive state of patients for the clinician. J Psychiatr Res. 1975;12(3):189-198. doi:10.1016/ 0022-3956(75)90026-6

17. Buysse DJ, Reynolds CF, Monk TH, Berman SR, Kupfer DJ. The Pittsburgh Sleep Quality Index: a new instrument for psychiatric practice and research. Psychiatry Res. 1989;28(2):193-213. doi:10.1016/0165-1781(89)90047-4 
18. Lawton MP, Brody EM. Assessment of older people: self-maintaining and instrumental activities of daily living. Gerontologist. 1969;9 (3):179-186. doi:10.1093/geront/9.3_Part_1.179

19. Kalia LV, Kalia SK, McLean PJ, Lozano AM, Lang AE. $\alpha$-Synuclein oligomers and clinical implications for Parkinson disease. Ann Neurol. 2013;73(2):155-169. doi:10.1002/ana.23746

20. Hao L, Guo X, Zou C, et al. Hyperbaric oxygen preconditioning ameliorates blood-brain barrier damage induced by hypoxia through modulation of tight junction proteins in an in vitro model. Croat Med J. 2016;57(1):51-57. doi:10.3325/cmj.2016.57.51

21. Long H, Peng G, Zhou C, et al. Study on PARK $\alpha$-synuclein gene mutation and polymorphism of minority patients with Parkinson. Chin J Control Endemic Dis. 2016;31(1):25-27.

22. Wang L, Zhang T, Yang X. Study on the prevalence and relative factors of the Parkinson's disease in residents aged 35 years or older in Urumqi city. J Xinjiang Med Univ. 2013;3:278-281.

23. Wang Y. Analysis of influencing factors of patients with different types of Parkinson's disease in Xining. Qinghai Univ. 2017

24. Uitti RJ, Baba Y, Wszolek ZK, Putzke DJ. Defining the Parkinson's disease phenotype: initial symptoms and baseline characteristics in a clinical cohort. Parkinsonism Relat Disord. 2005;11(3):139-145. doi:10.1016/j.parkreldis.2004.10.007

25. Zhang Y, Wang Y, Liu X. Man and Plateau Qinghai peolple's publishing house. 1996;6-7.

26. Veazey C, Aki SO, Cook KF, Lai EC, Kunik ME. Prevalence and treatment of depression in Parkinson's disease. J Neuropsychiatry Clin Neurosci. 2005;17(3):310-323. doi:10.1176/jnp.17.3.310

27. Pinto L, Alva Diaz C, Torres L. Associated factors with depressive symptoms in patients with Parkinson's disease. Med Clin (Barc). 2018;150(3):119-120. doi:10.1016/j.medcli.2017.07.022

28. Ruan W. The analysis on incidence of depression and related factors in Parkinson's disease In Xinjiang Region. Xinjiang Med Univ. 2013;1:45.

29. Ghaddar A, Fawaz M, Khazen G, Abdallah J, Milane A. Prevalence of depression in Parkinson's disease in a Lebanese tertiary clinic. $J$ Clin Exp Neuropsychol. 2016;38(1):51-58. doi:10.1080/ 13803395.2015.1087466

30. Dai Q, Li Z, Wang H. Characteristic and influencing factors of high blood pressure among Tibetan and Han elderly at different high altitude. J High Altitude Med. 2011;21(4):14-18.
31. Jorm LR, Walter SR, Lujic S, Byles JE, Kendig HL. Home and community care services: a major opportunity for preventive health care. BMC Geriatr. 2010;10:26. doi:10.1186/1471-2318-10-26

32. Hernán MA, Takkouche B, Caamaño-Isorna F, Gestal-Otero JJ. A meta-analysis of coffee drinking, cigarette smoking, and the risk of Parkinson's disease. Ann Neurol. 2002;52(3):276-284. doi:10.1002/ana.10277

33. Kim HS, Cheon SM, Seo JW, et al. Nonmotor symptoms more closely related to Parkinson's disease: comparison with normal elderly. $J$ Neurol Sci. 2013;324(1-2):70-73. doi:10.1016/j. jns.2012.10.004

34. Blanchet PJ, Brefel-Courbon C. Chronic pain and pain processing in Parkinson's disease. Prog Neuropsychopharmacol Biol Psychiatry. 2018;87(Pt B):200-206. doi:10.1016/j.pnpbp.2017.10.010

35. Kurtis MM, Rodriguez-Blazquez C, Martinez-Martin P. Relationship between sleep disorders and other non-motor symptoms in Parkinson's disease. Parkinsonism Relat Disord. 2013;19 (12):1152-1155. doi:10.1016/j.parkreldis.2013.07.026

36. LemosVde A, Antunes HK, Santos RV, et al. [Effects of exposure to altitude on neuropsychology aspects: a literature review]. Braz $J$ Psychiatry. 2010;32(1):70-76. Portuguese. doi:10.1590/s151644462009005000013

37. Papapetropoulos S, Ellul J, Argyriou AA, Chroni E, Lekka NP. The effect of depression on motor function and disease severity of Parkinson's disease. Clin Neurol Neurosurg. 2006;108(5):465-469. doi:10.1016/j.clineuro.2005.08.002

38. Simonson TS, Yang Y, Huff CD, et al. Genetic evidence for high-altitude adaptation in Tibet. Science. 2010;329(5987):72-75. doi: $10.1126 /$ science. 1189406

39. Li Z. The incidence of dementia in elderly Patients with cardiovascular and cerebrovascular diseases in Tibetan plateau area. China $J$ Geriatr Heart Brain Vessel Dis. 2013;15:2-6.

40. Piccinni A, Marazziti D, Veltri A, et al. Depressive symptoms in Parkinson's disease. Compr Psychiatry. 2012;53(6):727-731. doi:10.1016/j.comppsych.2011.11.002

41. Zhao $\mathrm{X}, \mathrm{Xu} \mathrm{C}$, Wang $\mathrm{C}$. Investigation and analysis of depression in the elderly in Qinghai Plateau. J High Altitude Med. 2005;15 (1):16-19.
Neuropsychiatric Disease and Treatment

\section{Publish your work in this journal}

Neuropsychiatric Disease and Treatment is an international, peerreviewed journal of clinical therapeutics and pharmacology focusing on concise rapid reporting of clinical or pre-clinical studies on a range of neuropsychiatric and neurological disorders. This journal is indexed on PubMed Central, the 'PsycINFO' database and CAS, and

\section{Dovepress}

is the official journal of The International Neuropsychiatric Association (INA). The manuscript management system is completely online and includes a very quick and fair peer-review system, which is all easy to use. Visit http://www.dovepress.com/testimonials.php to read real quotes from published authors. 